\title{
Preparation of Nickel Modified Carbon Fibre Electrodes and their Application for Methanol Oxidation
}

\author{
M.S. Risbud, S. Baxter and M. Skyllas-Kazacos", \\ School of Chemical Engineering, University of New South Wales, Sydney 2052, Australia
}

\begin{abstract}
Nickel modified carbon fibre electrodes were prepared by electrochemical oxidation and partial reduction of a graphite fibre electrode with a slow linear potential sweep in $97 \% \mathrm{H}_{2} \mathrm{SO}_{4}$ solution followed by impregnation \& ionexchange with $\mathrm{Ni}^{+2}$ species. The cyclic voltammetry of the modified electrode in an alkaline medium showed electrocatalytic activity towards methanol oxidation which is consistent with the behaviour of a polycrystalline nickel electrode in the same media. The electrode fabricated through the ion exchange with $0.1 \mathrm{M}$ Ni solution provided the most significant response for solutions with lower methanol concentrations up to $0.5 \mathrm{M}$ methanol while at higher concentrations of methanol, a poisoning effect was observed resulting in lower performance.
\end{abstract}

Keywords: Alkaline media, graphite fibre, ion exchange, methanol oxidation, nickel, surface modification.

\section{INTRODUCTION}

Direct methanol fuel cells (DMFCs) offer several advantages over their hydrogen counterparts especially for portable applications such as mobile phone chargers, notebook computers etc. Currently used $\mathrm{Pt}$ based electrocatalysts which are most widely investigated [1-6] make mass production difficult due to their low availability and expensive electrode costs. Also issues like $\mathrm{CO}$ poisoning severely affect the performance [7] of these cells. Alkaline direct methanol fuel cells are now receiving considerable attention because they allow the use of anion exchange membranes that reduce methanol cross-over - a serious problem with cation exchange membrane used in acidic methanol fuels [8]. Another reason for using alkaline medium is because the kinetics for both methanol oxidation and oxygen reduction reactions is found to be more facile in alkaline medium than in acidic one [9-12]. Even in the case of acidic DMFC however, nickel can in fact be used as a cocatalyst along with $\mathrm{Pt}-\mathrm{Ru}$ in an acidic medium [13] and Pt$\mathrm{Ru}-\mathrm{Ni} / \mathrm{C}$ shows better catalytic activity and more $\mathrm{CO}$ tolerance compared to $\mathrm{Pt}-\mathrm{Ru} / \mathrm{C}$ catalyst [13] The commercialization of these DMFCs is hindered by lower cell performance which can be attributed to slow anode kinetics $[14,15]$. In recent years, the focus of research is towards finding cheaper alternative electrocatalysts and improving the overall cell performance. Non noble transition metal electrocatalysts such as copper [16], nickel [17-24] which oxidise methanol and other alcohols, offer good alternative electrocatalysts. The activity of nickel based electrocatalysts depends on the method of preparation of these electrodes. Rahim et al., [24] showed that only nickel dispersed in graphite is catalytically active for methanol oxidation while massive nickel is not. Also this nickel electrocatayst, after

*Address correspondence to this author at the School of Chemical Engineering, University of New South Wales, Sydney 2052, Australia; Tel: +61-2-9385 4335; Fax:+61-2-9385 5966; E-mail: m.kazacos@unsw.edu.au

${ }^{\S}$ ISE member. continuous cycling looses its performance due to possible loss of activity of nickel oxide [24]. This is believed to be due to increased thickness of $\mathrm{NiO}(\mathrm{OH})$ which acts as a barrier inhibiting the charge transfer process for methanol oxidation. Alternative approaches to the preparation of nickel electrocatalysts that can minimise the build up of such a barrier layer, would be of great interest in the development of non-noble metal electrodes for methanol oxidation. Carbon fibre modified electrodes have been shown to form layers of metal ions distributed in the carbon matrix, creating active sites on the carbon surface instead of a continuous layer of deposited metal. The motivation behind this study is to investigate the effect of this carbon fibre modification and electrode preparation method on electrocatalytic activity towards methanol oxidation.

Since the discovery of the "chiral electrode" by Miller and co-workers [25], several reports have been published about the synthesis of chemically modified electrodes using Miller's amidization procedure [26, 27] or organosilane reagents [28-30] on either metal oxide or air oxidized carbon surfaces. In recent years, there has been considerable interest in the electrochemical properties of chemically modified electrodes involving surface oxidation [31-33] and surface functionalization [33-38]. Also the electrodeposition of several metals, such as $\mathrm{Ag}, \mathrm{Pb}, \mathrm{Cu}$ and $\mathrm{Au}$ on carbon fibre electrodes, has been investigated in detail. The deposition of these metals on the graphite fibre involved the exchange of their cations with the $\mathrm{H}$ ions of the acidic functional groups remaining in the graphite matrix after the incomplete cathodic reduction of the graphite oxide surface [38]. The electrochemical behaviour of platinised graphite fibre electrodes was studied by Jannakoudakis and co-workers [39]. These electrodes were prepared by deposition of platinum after ion exchange of residual graphite oxide fibres with various platinum compounds in aqueous solutions. These modified electrodes behave electrocatalytically just like bulk platinum electrodes [39]. These electrodes can be stored for long periods in distilled water without losing their mechanical stability and electrocatalytic activity. This same 
method has been used in the present study for the modification of graphite fibres via an ion exchange reaction with $\mathrm{Ni}^{+2}$ ions. The electrochemical behaviour of the chemically modified electrodes was investigated for the methanol oxidation reaction in an alkaline medium for possible applications in direct methanol fuel cells.

\section{EXPERIMENTAL}

All chemicals were of analytical grade and used without further purification. All electrolytic solutions were prepared using distilled water and $0.5 \mathrm{M}$ sodium hydroxide was used as a supporting electrolyte unless otherwise stated. All electrochemical studies were carried out in a standard threeelectrode glass cell using a Solartron SI 1287 potentiostat.

\subsection{Fabrication of Graphite Fibre Electrode}

A mechanically stable graphite fibre (Besfight, Toho Rayon Co. Ltd., Grade HTA-7-3000, bundle diameter $1 \mathrm{~mm}$ ) was used to fabricate the electrode employed in this study. The experimental electrode was prepared by forming a resin case around the carbon fibre placed in plastic holder such as a pipette tip (40 $\mathrm{mm}$ in length and $15 \mathrm{~mm}$ diameter). The resin mixture used was formed by mixing Epoxy resin (Araldite F) and hardener HY837. After the resin had dried, the electrode was surface polished with 240 grit sand paper to remove the excess epoxy to expose the graphite fibre cross-section that acted as the electrode surface. The electrode surface was finally polished with 1200 grit sand paper and washed repeatedly with distilled water prior to the electrochemical activation and ion exchange.

\subsection{Activation of Electrode}

The activation of the graphite fibre was achieved by using a slow linear voltage sweep of $2.5 \mathrm{mV} \mathrm{s}^{-1}$ in $97 \%$ $\mathrm{H}_{2} \mathrm{SO}_{4}$ electrolyte from an initial potential of $0 \mathrm{~V}$ to an upper voltage limit of $2.1 \mathrm{~V}$ (Vs SCE) and back [40]. This activation was carried out in the standard three-electrode cell with the graphite fibre electrode as working electrode while a saturated calomel electrode and carbon rod were used as reference and counter electrodes respectively. During the anodic sweep, the graphite fibre is electrochemically oxidised according to the following surface reactions [41]:

Reaction $1 \mathrm{C}_{n}+\mathrm{H}_{2} \mathrm{SO}_{4} \rightarrow \mathrm{C}_{n}^{+} \mathrm{HSO}_{4}^{-}+\mathrm{H}^{+}+e^{-}$

Reaction $2 \mathrm{C}_{n}^{+} \mathrm{HSO}_{4}^{-}+\mathrm{H}_{2} \mathrm{O} \rightarrow \mathrm{C}_{n} \mathrm{OH}+\mathrm{H}_{2} \mathrm{SO}_{4}$

$$
2 \mathrm{C}_{n} \mathrm{OH} \stackrel{\mathrm{O}}{\longrightarrow} 2 \mathrm{C}_{n} \mathrm{O}+\mathrm{H}_{2} \mathrm{O}
$$

This hydroxylated species $\left(\mathrm{C}_{\mathrm{n}} \mathrm{OH}\right)$ undergoes further oxidation readily to produce carbonyl or carboxyl functional groups.

Partial reduction occurs during the cathodic sweep as follows:

Reaction $3 \mathrm{C}_{n} \mathrm{O} \stackrel{\mathrm{H}^{+}}{\longrightarrow} \mathrm{C}_{n} \mathrm{O}^{-} \mathrm{H}^{+}$

The above surface oxidation and partial reduction enables formation of a high surface concentration of $-\mathrm{OH}$ groups that provide the active sites for ion exchange or impregnation by the metal [41]. To investigate the mechanism in detail the activation procedure was also repeated at $1 \mathrm{mV} \mathrm{s}^{-1}$ and $5 \mathrm{mV} \mathrm{s}^{-1}$.
The fibre electrode was then washed with distilled water for 10-15 minutes, and vacuum dried at room temperature for 20-25 hours. The vacuum reduction step was used for removal of any oxides formed [40].

\subsection{Cation Exchange with Nickel}

After the activation, the electrodes were placed in nickel sulphate solutions with different concentrations over a period of 50 hours during which impregnation or ion exchange takes place. The deposition of the nickel takes place through cation exchange with the hydrogen ions of the acidic functional groups left on the carbon surface after partial cathodic reduction of graphite oxide formed during activation $[39,40]$. After this procedure, the electrode was again washed thoroughly with distilled water and then vacuum dried at room temperature for 20-25 hours [40]. It was important to ensure that the electrode was left in distilled water between each stage, to reduce any oxide formation due to reaction with oxygen from the air prior to the methanol oxidation study.

\subsection{Electrochemical Studies}

The electrochemical studies were carried out using Solartron SI 1287 potentiostat in a standard three electrode glass cell where the graphite fibre electrode modified with nickel was employed as a working electrode for the methanol oxidation study, while a saturated calomel electrode (SCE) and graphite rod were used as reference and counter electrodes respectively. Solutions with various concentrations of methanol in $0.5 \mathrm{M} \mathrm{NaOH}$ were used as electrolytes. All experiments were carried out at room temperature and all potentials are reported vs SCE unless otherwise stated.

\section{RESULTS AND DISCUSSION}

\subsection{Graphite Fibre Activation and Characterisation}

Fig. (1) represents the cyclic voltammogram for the base graphite fibre electrode before activation and ion exchange. The electrolyte comprised of $0.5 \mathrm{M} \mathrm{NaOH}$ (blank) with increasing methanol concentrations from 0 to $0.5 \mathrm{M}$ methanol. As seen from the figure, there is no difference in the electrode response in the methanol solution and in the blank solution which proves that a base graphite fibre electrode does not catalyse the methanol oxidation reaction.

Fig. (2) shows the cyclic voltammogram for the activation of the graphite fibre electrode in $97 \% \mathrm{H}_{2} \mathrm{SO}_{4}$, prior to cationic exchange with $\mathrm{NiSO}_{4}$ solutions, as described in the experimental procedure. The aim of this activation step is to promote surface oxidation of the graphite fibres during the anodic scan from $0 \mathrm{~V}$ to $+2.1 \mathrm{~V}$, and incomplete or partial reduction of the oxide functional groups during the cathodic scan back from $+2.1 \mathrm{~V}$ to $0 \mathrm{~V}$. Three separate peaks $\left(\mathrm{a}_{1}, \mathrm{a}_{2}\right.$ during the anodic sweep and $\mathrm{c}_{1}$ during the cathodic sweep) are observed. The first peak $\mathrm{a}_{1}$ at around $0.7 \mathrm{~V}$ represents the formation of $\mathrm{C}_{\mathrm{n}}^{+} \mathrm{HSO}_{4}^{-}\left(\mathrm{H}_{2} \mathrm{SO}_{4}\right)$ salts formed between graphite bulk and the sulphuric acid electrolyte which is then oxidised further to a partly covalent graphite oxide at the second peak $\mathrm{a}_{2}$ at around $1.4 \mathrm{~V}$ according to reaction 1 and 2 above [40]. During the cathodic scan, only partial reduction of the graphite oxide formed during the anodic sweep, occurs at the third peak $\mathrm{c}_{1}$ at around $0.4 \mathrm{~V}$, resulting in formation of 
-OH surface groups [40] on the graphite fibre according to Reaction 3, which will allow for subsequent cationic exchange with nickel ions to form graphite-nickel electrodes according to reaction 4 [41]:

Reaction $4 \mathrm{C}_{n} \mathrm{O}^{-} \mathrm{H}^{+}+\mathrm{Ni}^{+2} \rightarrow\left(\mathrm{C}_{n} \mathrm{O}^{-}\right)_{2} \mathrm{Ni}^{+2}$

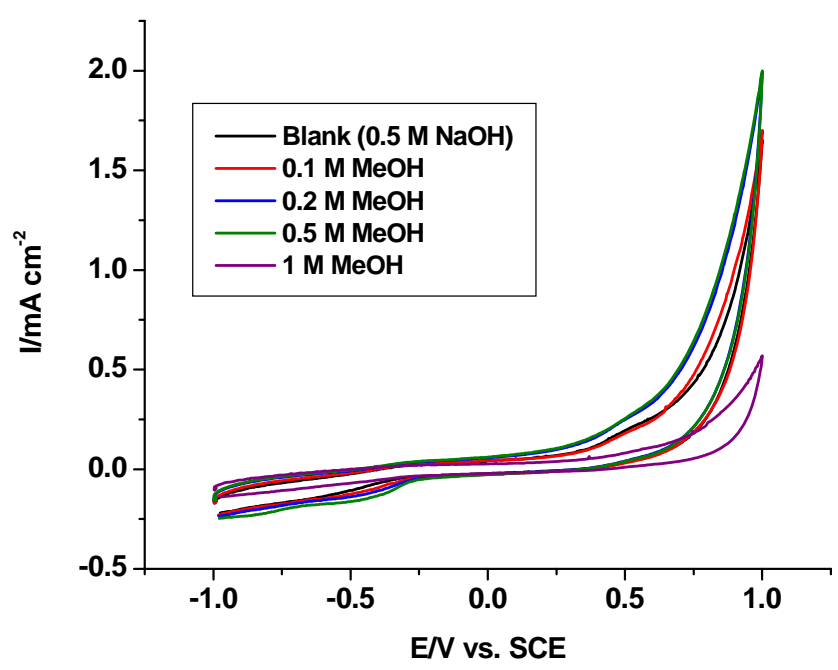

Fig. (1). Methanol oxidation at base graphite electrode (no modification) in $0.5 \mathrm{M} \mathrm{NaOH}$ solutions, $25 \mathrm{mV} \mathrm{s}^{-1}$ scan rate.

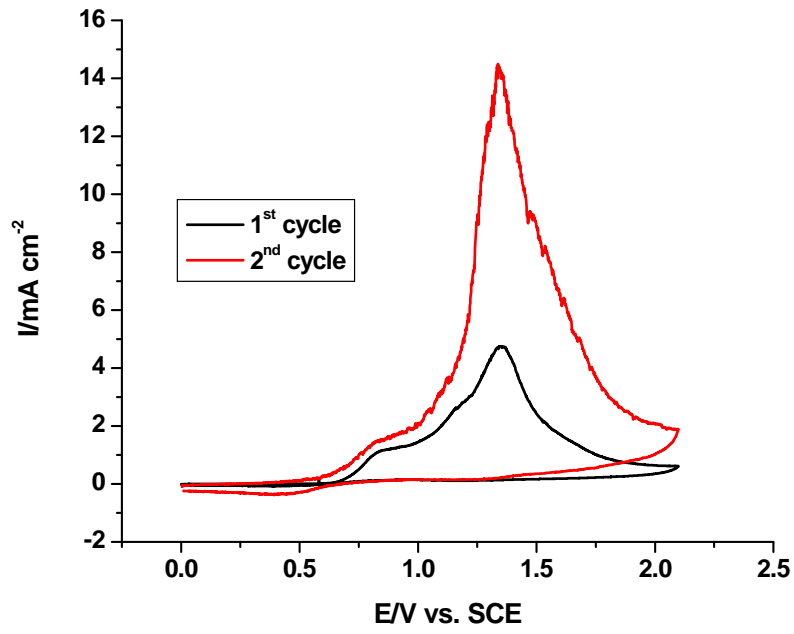

Fig. (2). Activation of graphite fibre electrode in $97 \% \mathrm{H}_{2} \mathrm{SO}_{4}$, scan rate $2.5 \mathrm{mV} \mathrm{s}^{-1}$.

Fig. (3) shows the activation process at various scan rates. Typical results obtained for methanol oxidation with the 'activated' graphite fibre electrode, prior to any cationic exchange with nickel are presented in Fig. (4). The electrolyte solutions comprised a base $0.5 \mathrm{M} \mathrm{NaOH}$ with increasing concentration of methanol. As seen in the figure, the current response is quite low, with no significant anodic peak for methanol oxidation observed.

Cyclic voltammograms obtained at the graphite fibre electrodes in $0.5 \mathrm{M} \mathrm{NaOH}$ after activation and ion exchange are illustrated in Fig. (5). By comparing the response of this electrode with the response for a nickel foil electrode (shown in the inset in Fig. 5), the nickel modified graphite fibre electrode is seen to behave like a nickel electrode. Anodic peak at approximately $0.5 \mathrm{~V}$ vs SCE in both curves (b) and inset of Fig. (5) correspond to the oxidation of $\mathrm{Ni}^{+2}$ to $\mathrm{Ni}^{+3}$ according to [24]:

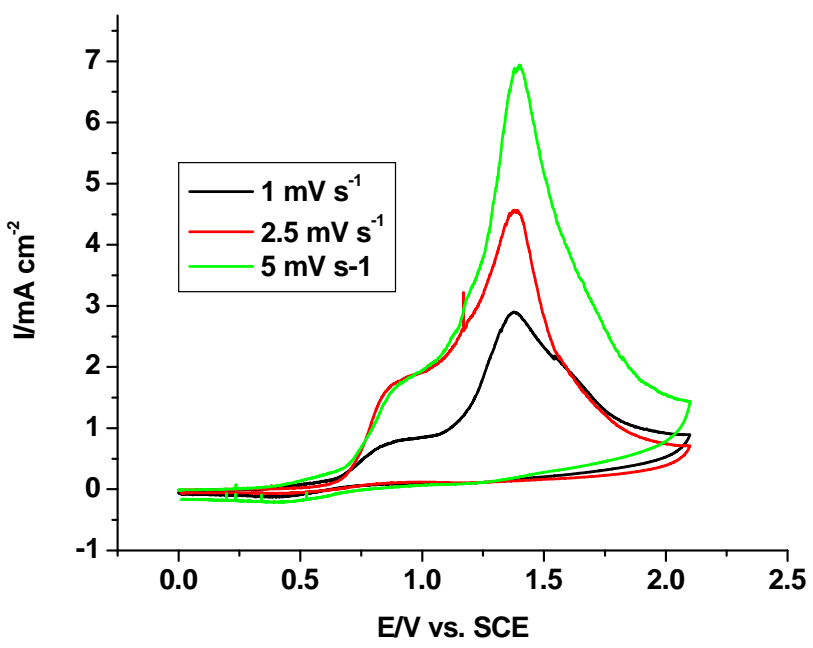

Fig. (3). Activation of Graphite Fibre Bulk in $97 \% \mathrm{H}_{2} \mathrm{SO}_{4}$ solution, at $1 \mathrm{mV} \mathrm{s}^{-1}, 2.5 \mathrm{mV} \mathrm{s}^{-1}, 5 \mathrm{mV} \mathrm{s}^{-1}$ scan rate.

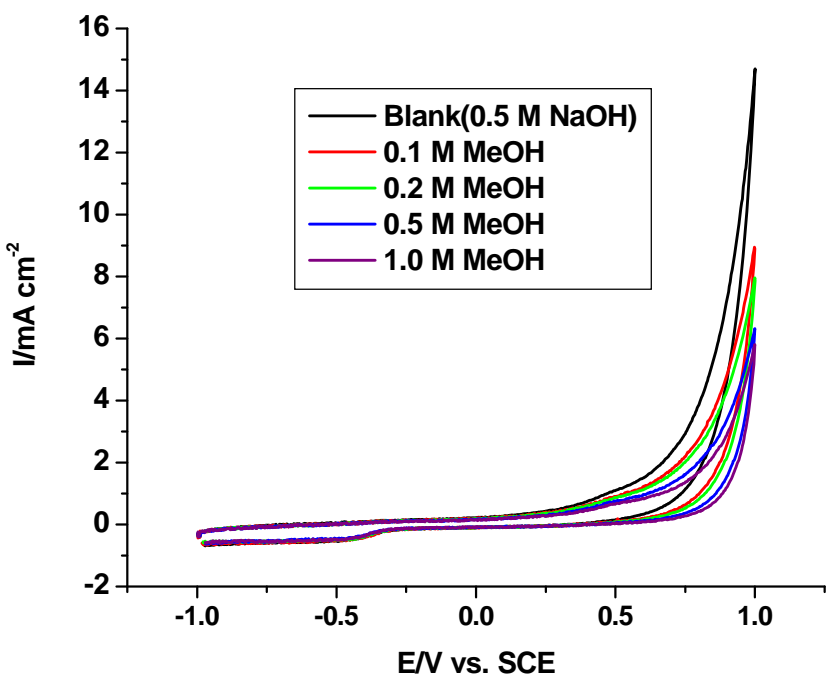

Fig. (4). Methanol oxidation in $0.5 \mathrm{M} \mathrm{NaOH}$ solutions, at residual graphite electrode (activation in $\mathrm{H}_{2} \mathrm{SO}_{4}$, no Ni ion ex.), at $25 \mathrm{mV} \mathrm{s}$ scan rate.

Reaction $5 \mathrm{Ni}^{+2} \rightarrow \mathrm{Ni}^{+3}+e^{-}$

During the cathodic sweep, a reduction peak is observed at around $0.3 \mathrm{~V}$ corresponding to the reduction of $\mathrm{Ni}^{+3}$ to $\mathrm{Ni}^{+2}$.

Reaction 6. $\mathrm{Ni}^{+3}+e^{-} \rightarrow \mathrm{Ni}^{+2}$

while at $-0.6 \mathrm{~V}$, a second cathodic peak is observed corresponding to the reduction of dissolved oxygen from the solution. This peak is absent in case of nickel foil as the strongly adsorbed oxygen on nickel foil is not reduced as easily. This is due to the fact that smooth nickel is very sensitive to dissolved oxygen from solution and it gets strongly adsorbed on the surface [42]. Here in addition to 


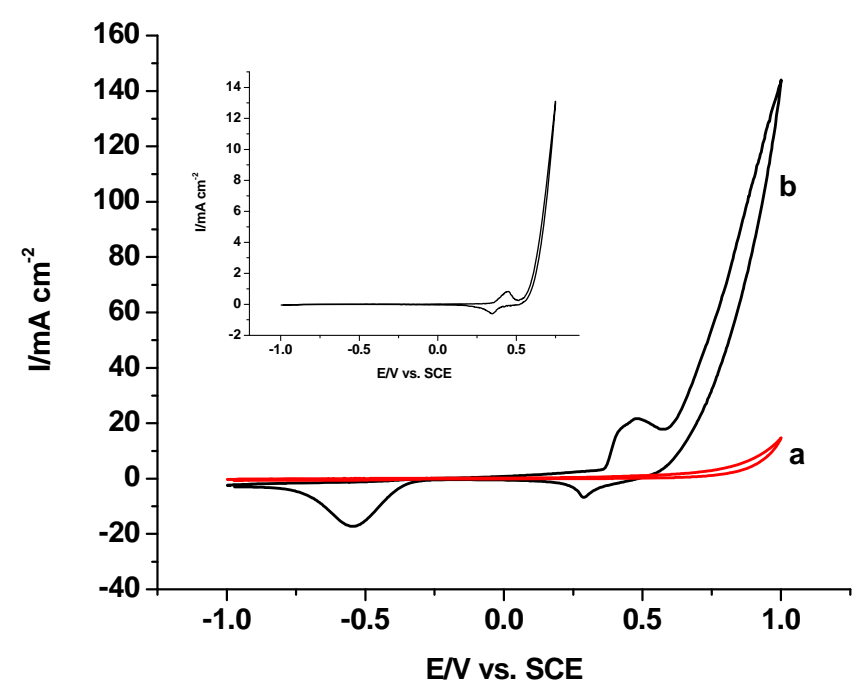

Fig. (5). Cyclic voltammogram for Ni-modified graphite fibre electrode in $0.5 \mathrm{M} \mathrm{NaOH}$ solution; corresponding response for Nickel foil in inset.

oxygen reduction, there is also possibility of reduction of carboxyl functional groups. Fig. (2) indicates even without any activation and modification, the electrode shows reduction peak around $-0.5 \mathrm{~V}$ (which could only be due to dissolved oxygen) and the same peak area increases after activation and modification which may suggest the possible partial reduction of carboxyl functional groups.

Another observation is while the $\mathrm{Ni}(\mathrm{OH})_{2} / \mathrm{NiOOH}$ transformation occurs reversibly on bulk nickel (as noted from the potential peak separation), on dispersed nickel, this transformation occurs quasi-reversibly or irreversibly. This could possibly be due to the IR drop across the graphite substrate. Also the shape of the $\mathrm{Ni}$ (II) / Ni (III) transition (i.e. peak separation, peak current ratios and peak potentials), is influenced by the thickness of the nickel film [24] and for thicker deposited nickel oxide films, the voltammogram begins to show the typical features of an electrode with higher resistance. In contrast, the activated graphite fibre electrode with no Ni ion exchange (Fig. 4) shows no anodic or cathodic peaks at 0.5 and $0.3 \mathrm{~V}$ respectively, confirming the absence of any $\mathrm{Ni}$ on the electrode surface before modification.

The amount of nickel deposited on the surface of graphite fibre was estimated from the calculation of the charge transferred during the nickel oxidation reaction in $0.5 \mathrm{M}$ $\mathrm{NaOH}$ in the absence of methanol (peak around $0.5 \mathrm{~V}$ in Fig. 5). The charge was calculated by converting the $\mathrm{E}$ axis to time and then integrating the I-t curve. Other analytical methods like XPS failed to detect any deposited nickel (in case of $0.1 \mathrm{M}, 0.2 \mathrm{M} \mathrm{Ni}$ samples); however this may be attributed to difficulties with sample preparation when embedding the electrode in resin, as well as the very small quantity of nickel that may not be detectable using XPS or other analytical techniques. From the charge calculations, the amount of nickel deposited on the carbon fibre electrode during the ion exchange is calculated and shown in Table $\mathbf{1 .}$

Surprisingly, the amount of $\mathrm{Ni}$ on the electrode surface, as calculated from the charge transferred during the oxidation of $\mathrm{Ni}^{+2}$ to $\mathrm{Ni}^{+3}$ appears to decrease as the $\mathrm{Ni}^{+2}$ ion concentration in the ion exchange solution increases from 0.2 to $0.5 \mathrm{M}$. This effect will be discussed further later.

Assuming an approximate electrode surface area of $0.007855 \mathrm{~cm}^{2}$ and an atomic radius for $\mathrm{Ni}$ of $124 \mathrm{pm}$, a surface coverage of approximately $3.2 \times 10^{5}$ atoms/layer is calculated for the electrode modified in $0.1 \mathrm{M} \mathrm{NiSO}$, showing that there are multiple atomic layers of $\mathrm{Ni}$ on the electrode surface indicating activation of sites on the surface as well as in the bulk.

\subsection{Methanol Oxidation Results}

These $\mathrm{Ni}$ modified electrodes were tested for their electrocatalytic activity towards methanol oxidation and the results are depicted in Figs. (6-8) which represent results for electrodes modified by ion exchange in $0.1 \mathrm{M}, 0.2 \mathrm{M}$ and 0.5 $\mathrm{M} \mathrm{NiSO}_{4}$ solutions respectively. The electrolytes comprised of varying concentrations of methanol in $0.5 \mathrm{M} \mathrm{NaOH}$. Corresponding voltammograms are also presented for the modified electrodes in $0.5 \mathrm{M} \mathrm{NaOH}$ as the blank electrolyte.

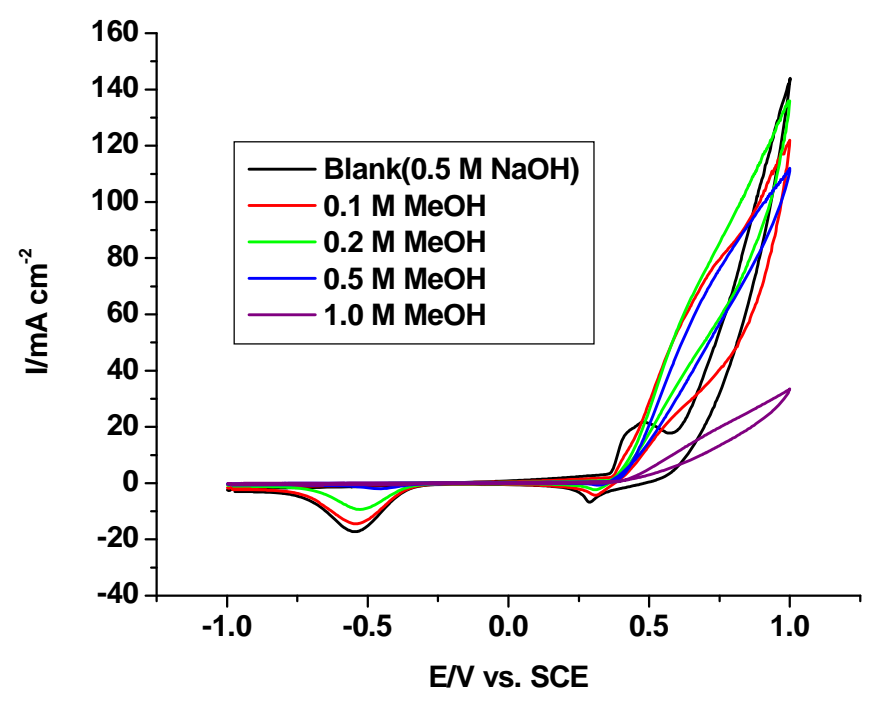

Fig. (6). Methanol oxidation in $0.5 \mathrm{M} \mathrm{NaOH}$ solution, at graphitenickel electrode ( $0.1 \mathrm{M} \mathrm{Ni}$ ion ex.), at $25 \mathrm{mV} / \mathrm{s}$ Scan Rate.

Table 1. Calculation for Amount of Nickel in the Modified Carbon Fibre Electrodes

\begin{tabular}{|c|c|c|c|}
\hline Electrode & Charge (Coulombs) & No. of Moles & No. of Atoms \\
\hline \hline $0.1 \mathrm{M}$ Ni modified & $1.21 \times 10^{-6}$ & $1.26 \times 10^{-11}$ & $7.56 \times 10^{12}$ \\
\hline $0.2 \mathrm{M}$ Ni modified & $4.72 \times 10^{-7}$ & $4.90 \times 10^{-12}$ & $2.95 \times 10^{12}$ \\
\hline $0.5 \mathrm{M}$ Ni modified & $1.4 \times 10^{-8}$ & $1.55 \times 10^{-13}$ & $9.36 \times 10^{10}$ \\
\hline
\end{tabular}




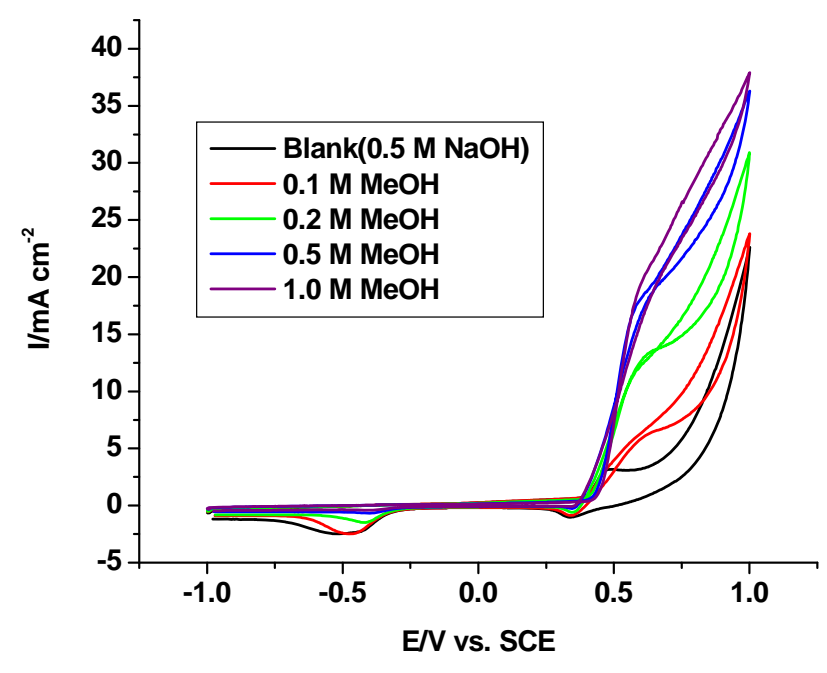

Fig. (7). Methanol oxidation in $0.5 \mathrm{M} \mathrm{NaOH}$ solution, at graphitenickel electrode ( $0.2 \mathrm{M} \mathrm{Ni}$ ion ex.), at $25 \mathrm{mV} / \mathrm{s}$ Scan Rate.

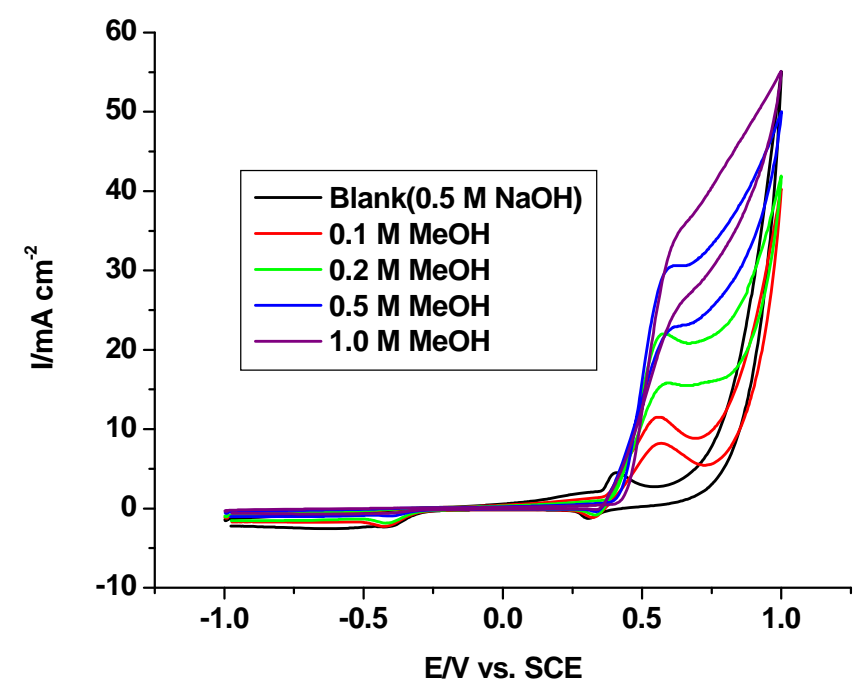

Fig. (8). Methanol oxidation in $0.5 \mathrm{M} \mathrm{NaOH}$ solution, at graphitenickel electrode ( $0.5 \mathrm{M}$ Ni ion ex.), at $25 \mathrm{mV} / \mathrm{s}$ Scan Rate.

Fig. (6) shows that in the absence of methanol, an anodic peak appears at around $0.45 \mathrm{~V}$ with the corresponding cathodic peak at around $0.3 \mathrm{~V}$, these being attributed to the $\mathrm{Ni}$ (II)/ Ni (III) couple [24]. There is also another cathodic peak at around $-0.6 \mathrm{~V}$ which is attributed to reduction of dissolved oxygen and also partial reduction of carboxyl groups from the carbon matrix. This behaviour is consistent with that of a polycrystalline nickel electrode confirming that the graphite fibre electrode has been successfully modified with nickel. In the presence of methanol, another anodic peak appears at $0.6 \mathrm{~V}$ which is consistent with the oxidation potential of methanol at polycrystalline nickel. Increasing the methanol concentration in the electrolyte solution results in an initial increase in the peak response up to a methanol concentration of $0.2 \mathrm{M}$, followed by a decreasing response with a further increase in methanol concentration. The probable reason for this appears to be a poisoning of the electrode due to accumulation of methanol oxidation products on the surface. Similar results were obtained for the electrodes modified by ion exchange in $0.2 \mathrm{M}$ and $0.5 \mathrm{M}$
$\mathrm{NiSO}_{4}$ solutions. A comparison of these results with those in Figs. (7, 8) shows that the electrode modified in $0.1 \mathrm{M}$ Nickel gives a higher current response than that for electrodes modified in $0.2 \mathrm{M}$ and $0.5 \mathrm{M} \mathrm{NiSO}_{4}$ solutions. In contrast to the electrode modified in $0.1 \mathrm{M} \mathrm{NiSO}_{4}$ however the graphite fibre electrodes modified in $0.2 \mathrm{M}$ and $0.5 \mathrm{M}$ $\mathrm{NiSO}_{4}$ shows a consistent trend of an increasing anodic current response with increasing methanol concentration.

Fig. (9) shows the overlay response for activated graphite fibre electrode (no Ni modification) in $0.1 \mathrm{M} \mathrm{MeOH}$ solution and those for the activated electrodes modified with $0.1 \mathrm{M}$, $0.2 \mathrm{M}$ and $0.5 \mathrm{M} \mathrm{NiSO}_{4}$ solutions. As seen in the figure, the response for the $0.1 \mathrm{M} \mathrm{Ni}$ modified electrode is higher than that for higher Ni concentration modified electrodes. Abdel Rahim et al., [41] showed that for $\mathrm{Ni}$ electrodeposited on graphite electrode, increasing $\mathrm{Ni}$ deposition does not result in a linear increase in current density for methanol oxidation. However there is dramatic increase in current density at low nickel concentration resulting in a maximum followed by a drop in current density at higher concentrations.

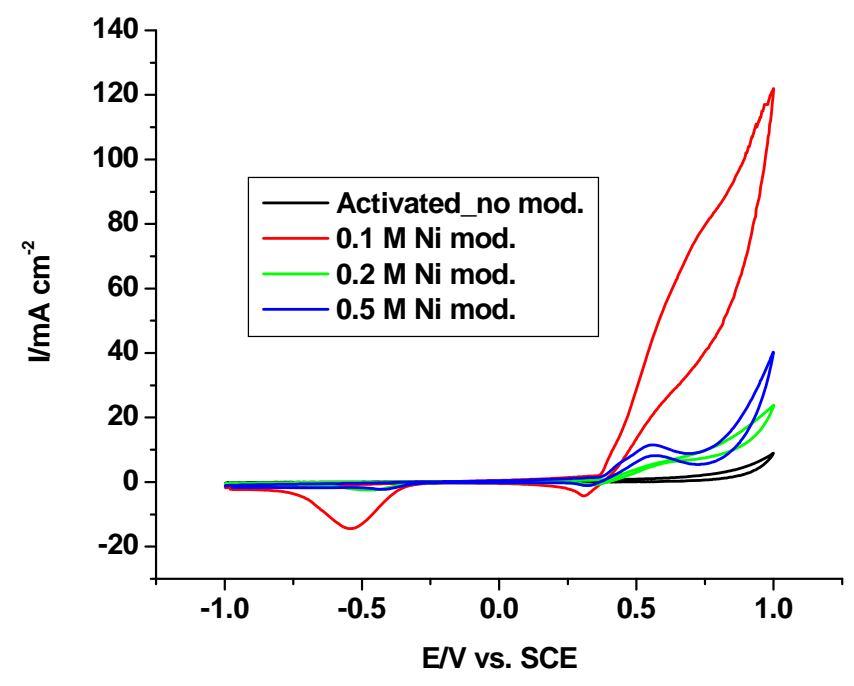

Fig. (9). Methanol oxidation at electrodes with increasing graphitenickel concentration $(0.1 \mathrm{M} \mathrm{MeOH}$ for $0.1 \mathrm{M} \mathrm{Ni}$, "Activated', $0.2 \mathrm{M}$ $\mathrm{Ni}$ and $0.5 \mathrm{M} \mathrm{Ni}$ ) in $0.5 \mathrm{M} \mathrm{NaOH}$ solution, at $100 \mathrm{mV} / \mathrm{s}$ Scan Rate.

This behaviour is shown in Fig. (10). The reason for this significant increase in current density for the methanol oxidation on the $0.1 \mathrm{M}$ nickel electrode is not clearly understood. One suggestion is that at lower nickel concentrations the electrode has a higher catalytic surface area available for reaction due to greater dispersion on the surface of the graphite fibres [42]. This is similar to an opinion that with an increase in surface concentration, the layers of nickel become denser on the graphite surface approaching the behaviour of a 'massive nickel electrode' [18]. However, as previously calculated from charge calculations, there was higher surface $\mathrm{Ni}$ concentration on the electrode that was modified in $0.1 \mathrm{M} \mathrm{NiSO}_{4}$ solution. On the other hand the Ni modified graphite electrodes formed in $0.2 \mathrm{M}$ and $0.5 \mathrm{M}$ nickel ion exchange solutions showed lower surface $\mathrm{Ni}$ concentration and in turn, demonstrate a lower catalytic effect for methanol oxidation. While the explanation for better performance for $0.1 \mathrm{M} \mathrm{Ni}$ modified electrode can be given by an increased number of atoms of 
nickel deposited on the surface, the exact reason behind the higher deposition of nickel in the case of the $0.1 \mathrm{M} \mathrm{Ni}$ modified electrode compared to $0.2 \mathrm{M}$ and $0.5 \mathrm{M} \mathrm{Ni}$ electrodes is still not understood.

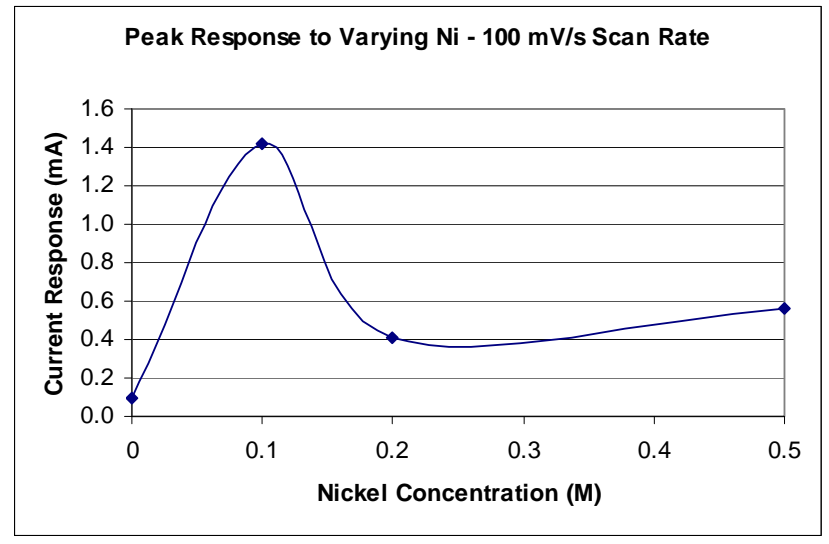

Fig. (10). Average Current Response compared for electrodes with increasing graphite-nickel concentration for methanol oxidation $(0.1 \mathrm{M} \mathrm{MeOH}$ for $0.1 \mathrm{M} \mathrm{Ni}$, 'Activated', $0.2 \mathrm{M} \mathrm{Ni}$ and $0.5 \mathrm{M} \mathrm{Ni}$ ) in $0.5 \mathrm{M} \mathrm{NaOH}$ solution, at $100 \mathrm{mV} / \mathrm{s}$ Scan Rate.

Another opinion is that for thin nickel oxides catalysts, the oxidation of methanol proceeds with direct chemical reaction with $\mathrm{NiO}(\mathrm{OH})$ produced electrochemically during anodic sweep [18]; while for graphite-nickel electrodes prepared at higher $\mathrm{Ni}$ concentrations, oxidation of methanol proceeds by charge transfer, resulting in a decrease in catalytic activity [18]. This is believed to be caused by the increase of $\mathrm{NiO}(\mathrm{OH})$ produced at the surface of the electrode inhibiting the effective oxidation of methanol rather than promoting it [18].

However this is not consistent with Fleischmann et al., [17], who suggested a mechanism that methanol oxidation is the result of nickel species changing from one state to the next, and an accumulation of $\mathrm{NiO}(\mathrm{OH})$ should in turn lead to an increase in the oxidation of methanol. The mechanism suggested is as follows.

$$
\begin{aligned}
& \mathrm{Ni}(\mathrm{OH})_{2 \text { (ads.) }} \rightarrow \mathrm{NiOOH}+e^{-}+\mathrm{H}^{+} \\
& \mathrm{NiOOH}+\mathrm{CH}_{3} \mathrm{OH}_{\text {(ads.) }} \rightarrow \mathrm{Ni}(\mathrm{OH})_{2}+\left[\mathrm{CH}_{2} \mathrm{OH}\right]+\mathrm{H}_{2} \mathrm{O}
\end{aligned}
$$

It is quite possible that the reality is a combination of these opinions and that the Fleischmann et al., suggested mechanism of the promotion of organic compound oxidation does not follow a linear progression. It is possible that the true mechanism is not a one way reaction but rather approaches equilibrium and that there is a critical methanol concentration at which inhibition of further oxidation takes place. Further experimentation is necessary to confirm these suggestions.

\subsection{Deterioration of Nickel Modified Electrode}

The Fig. (11a, b) represent the effect of extended operation of the $\mathrm{Ni}$ modified working electrodes under potentiostatic electrolysis in a $0.5 \mathrm{M} \mathrm{MeOH}$ solution at $0.6 \mathrm{~V}$ and $0.65 \mathrm{~V}$ vs SCE, the voltage at which $\mathrm{NiO}(\mathrm{OH})$ would begin to form on the surface of the working electrodes. This also correlates to the potential at which methanol oxidation begins to be significantly promoted. The figures show a slight increase in current over the extended period of operation. It is likely that this increase in activity of both electrodes over the extended period was due to an increase in the formation of $\mathrm{Ni}$ (III) species thereby allowing more efficient oxidation of the methanol in solution. This is confirmed in Fig. (12) where a cyclic voltammogram recorded in $0.5 \mathrm{M}$ methanol in $0.5 \mathrm{M} \mathrm{NaOH}$ after polarization shows a significant increase in current density compared to the response before polarization.

It was observed that the nickel electrodes prepared by electrodeposition of nickel on graphite disks lose their electrocatalytic activity due to formation of a thick layer of $\mathrm{NiO}(\mathrm{OH})$ which inhibits charge transfer (discussed in detail in section 1) and have to be reduced back to nickel in order to regain their activity [18]. In our studies, a potentiostatic treatment at $0.65 \mathrm{~V}$ vs SCE, improves the electrocatalytic activity. In previous studies [24], the whole electrode surface is covered by nickel and with continuous cycling, there is increase in the thickness of $\mathrm{Ni}$ (III) layer making the electrode to behave very similar to bulk nickel and hence lower catalytic activity. In our studies, nickel is likely to be dispersed in the carbon matrix instead of a continuous layer and during the potentiostatic studies, even though there is a increase in $\mathrm{Ni}(\mathrm{III})$ formation, the layer of $\mathrm{Ni}$ (III) is not continuous. Electrical conduction to the carbon matrix is therefore facilitated and hence the better activity compared to electrodeposited electrode.

Although these results can not conclude that there is no deterioration of the electrodes after extended electrolysis, a slight increase in activity was observed and this may be due to exposure of a greater surface area of the working electrode or the accumulation of $\mathrm{NiO}(\mathrm{OH})$ species in the carbon matrix that may be linked to the increase in oxidation as predicted by Fleischmann et al., (1971) [17]. Further experimentation is required to determine the actual cause of the phenomenon however.

\subsection{XPS Studies}

Carbon fibre without any resin was used as a substrate for activation in $97 \% \mathrm{H}_{2} \mathrm{SO}_{4}$ for XPS studies to avoid the interference of resin. Another electrode modified with nickel after activation was also used to study the nature of bonding and presence of nickel and results are presented in this section.

Fig. (13) represents wide angle spectra for an activated carbon fibre without any ion exchange (a) and nickel modified electrode (b) while the individual binding energy spectra for carbon, sulphur and oxygen are shown in Fig. (14).

In Fig. (14a), the peak at around $288.8 \mathrm{eV}$ corresponds to $\mathrm{O}=\mathrm{C}=\mathrm{O}$ group while the peaks at 286.2 and $285.6 \mathrm{eV}$ correspond to $\mathrm{C}=\mathrm{O}$ and $\mathrm{C}-\mathrm{O}$ binding energies. The peak at $284.6 \mathrm{eV}$ is due to either $\mathrm{C}-\mathrm{C}$ or $\mathrm{C}-\mathrm{H}$ group [43]. In Fig. $(\mathbf{1 4 b}, \mathbf{c})$, the peaks at 532.1 and $533.5 \mathrm{eV}$ are due to $\mathrm{S}=\mathrm{O}$ and $\mathrm{S}-\mathrm{O}$ respectively while sulphur shows peak at $169.02 \mathrm{eV}$ corresponding to sulphate ion [43]. 
(a)

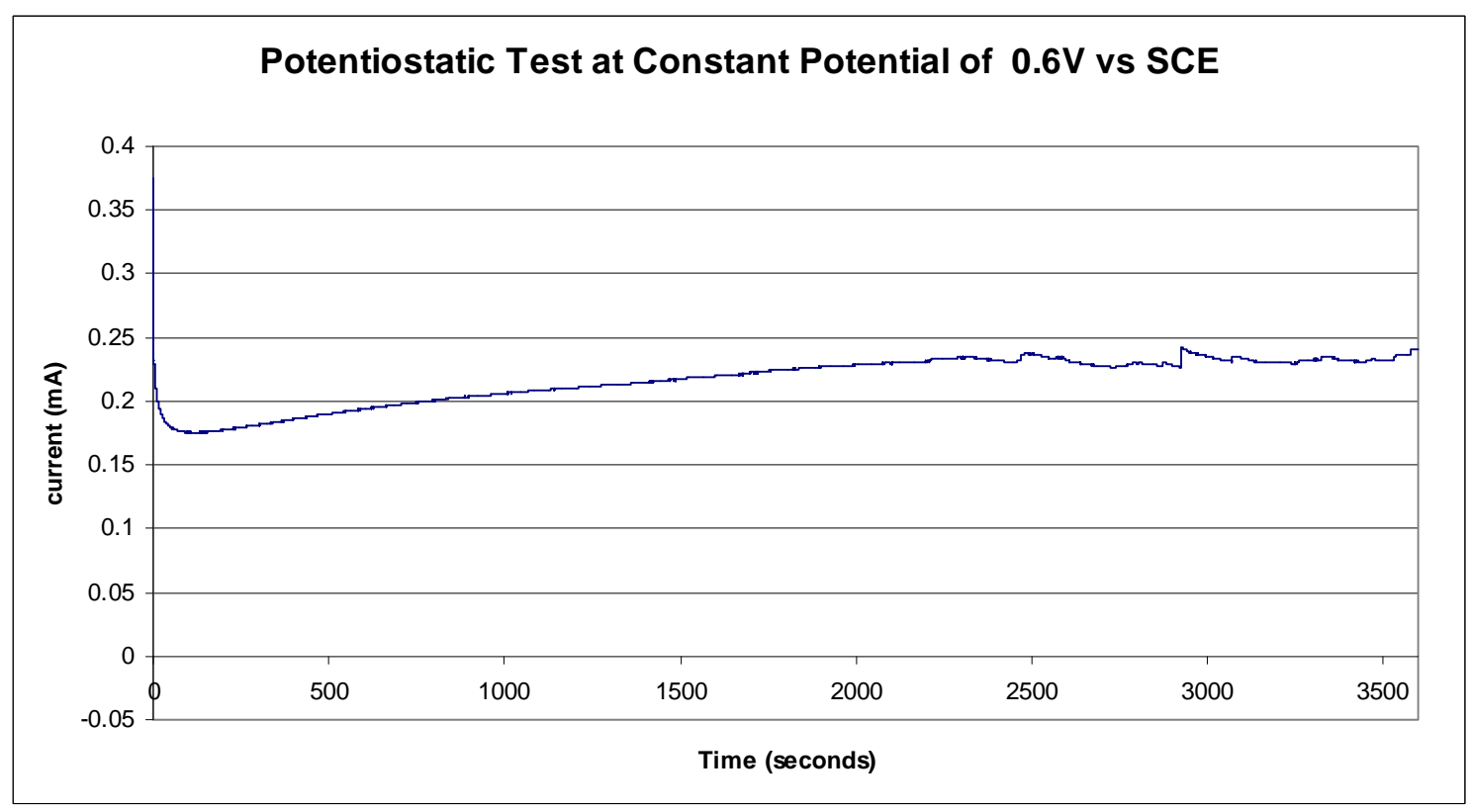

\section{Potentiostatic Test at Constant Potential of $0.65 \mathrm{~V}$ vs SCE}

(b)

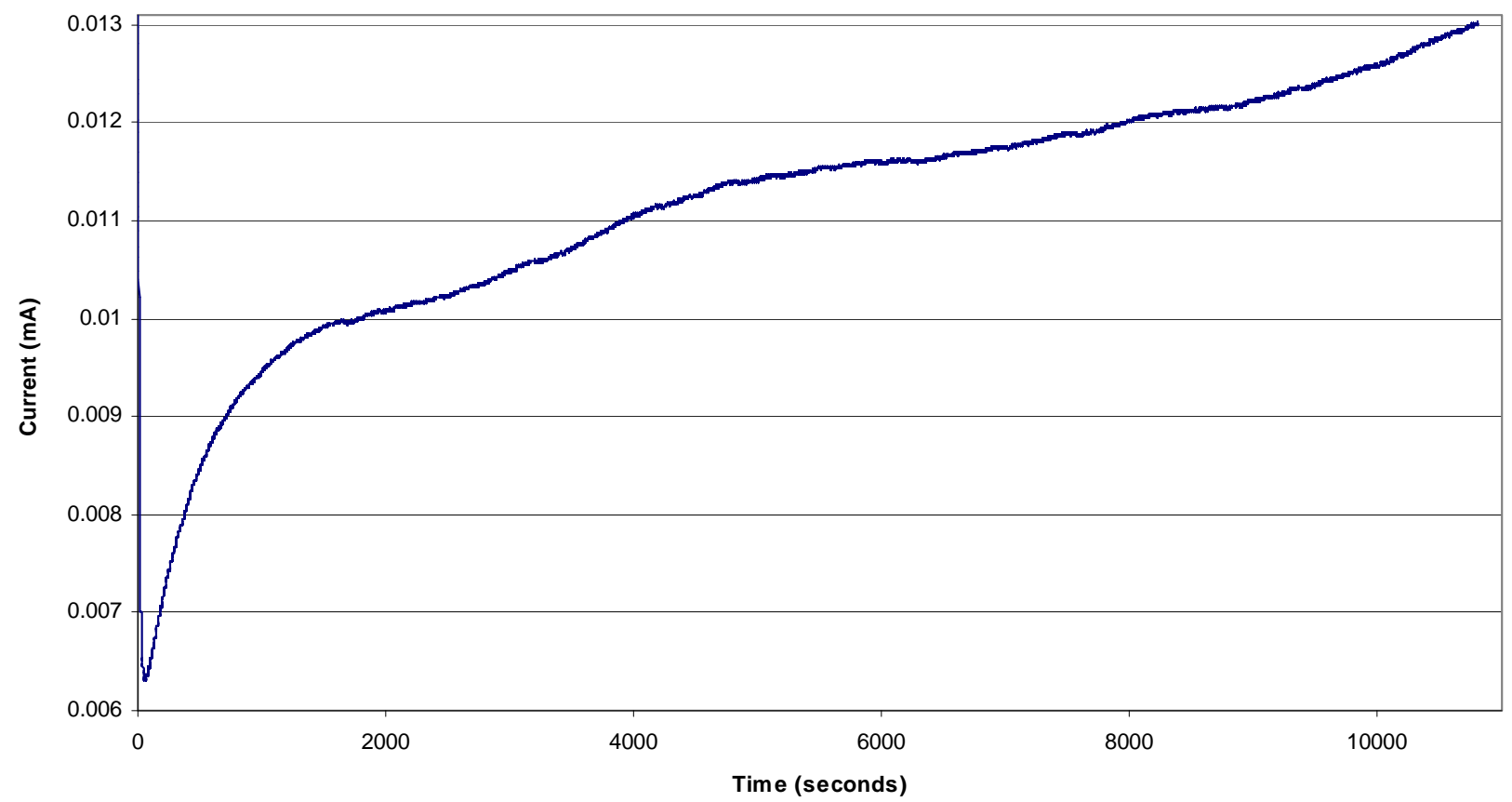

Fig. (11). Extended Activity of graphite-nickel electrode $(0.2 \mathrm{M} \mathrm{Ni}$ ion ex.) in $0.5 \mathrm{M} \mathrm{MeOH}$ and $0.5 \mathrm{M} \mathrm{NaOH}$, (a) at a constant potential of $0.6 \mathrm{~V} v s$ SCE over 1 hour, (b) at a constant potential of $0.65 \mathrm{~V} v s$ SCE over 3 hours.

Therefore it is confirmed from XPS spectra that there is a presence of sulphate ion in the carbon fibre matrix after the activation process despite thorough washing with distilled water. The S2p3 state of sulphur is due to presence of sulphuric acid in the carbon matrix and hence there is possibility of expansion of carbon fibre matrix during the activation. In that case the active functional groups are also created in the bulk of the expanded matrix where metal modification is possible through ion exchange. This explains the multiple layers of coverage discussed in section 3.1 for nickel.

XPS spectra were also recorded for the $\mathrm{Ni}$ modified carbon fibre electrodes (without vacuum drying step after ion 


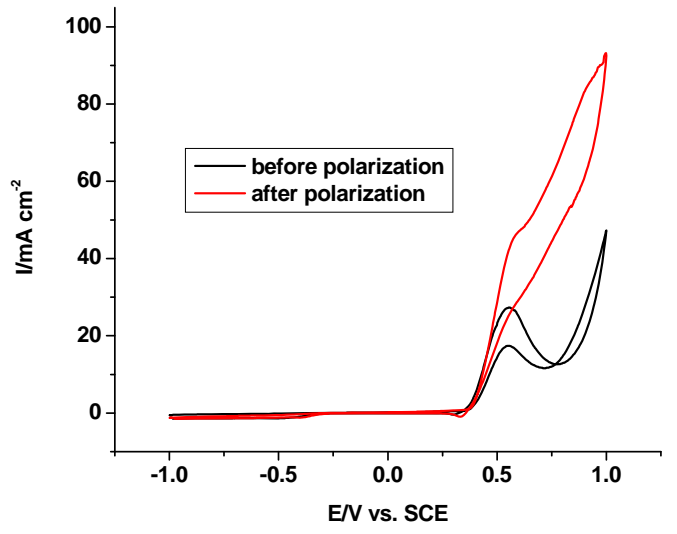

Fig. (12). Cyclic voltammogram obtained in $0.5 \mathrm{M} \mathrm{MeOH}$ in $0.5 \mathrm{M}$ $\mathrm{NaOH}$ for $0.1 \mathrm{M}$ Ni modified electrode before and after polarization. exchange) and the results for wide angle measurements and individual measurements for carbon, oxygen, sulphur are similar to those obtained for carbon fibre without any modification while (d) represents the corresponding measurement for $\mathrm{Ni}$.

In case of $\mathrm{Ni}$ spectrum, the peak at binding energy value 856.0 which corresponds to $\mathrm{Ni}(\mathrm{II})$ oxidation state and represent bond energy for $\mathrm{Ni}=\mathrm{O}$ group [43].

Therefore from XPS studies, it is clear that the activation of carbon fibre occurs not only on the surface but also in the bulk of the fibre creating layer like structure with gaps created due to expansion of carbon matrix by $\mathrm{H}_{2} \mathrm{SO}_{4}$ molecule.

As seen from previous work carried out in our lab, copper displayed increased catalytic activity with increasing

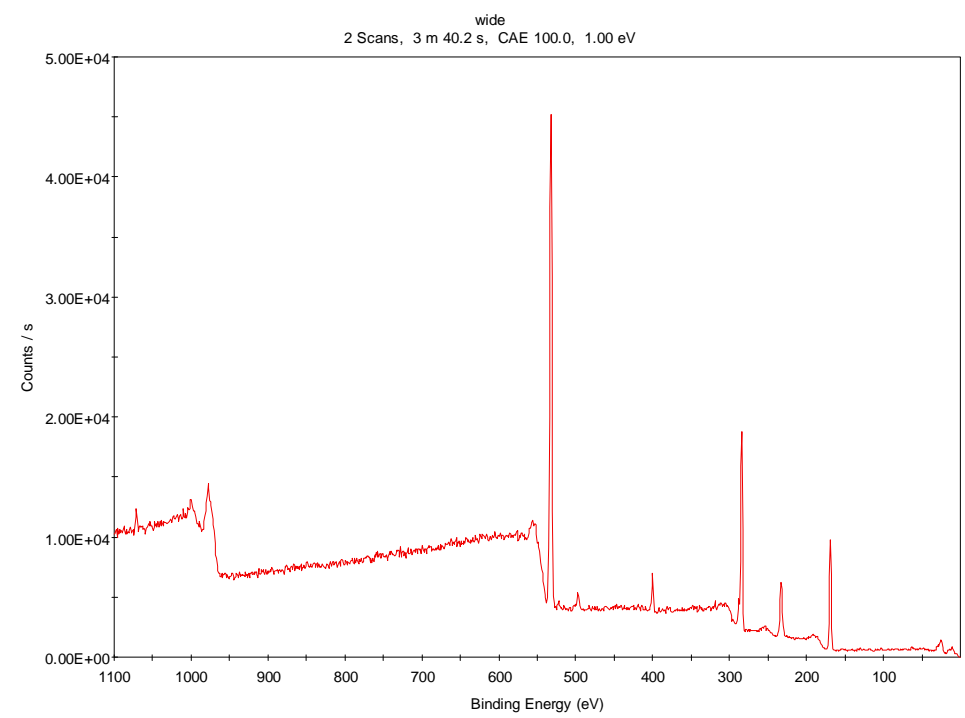

(a)

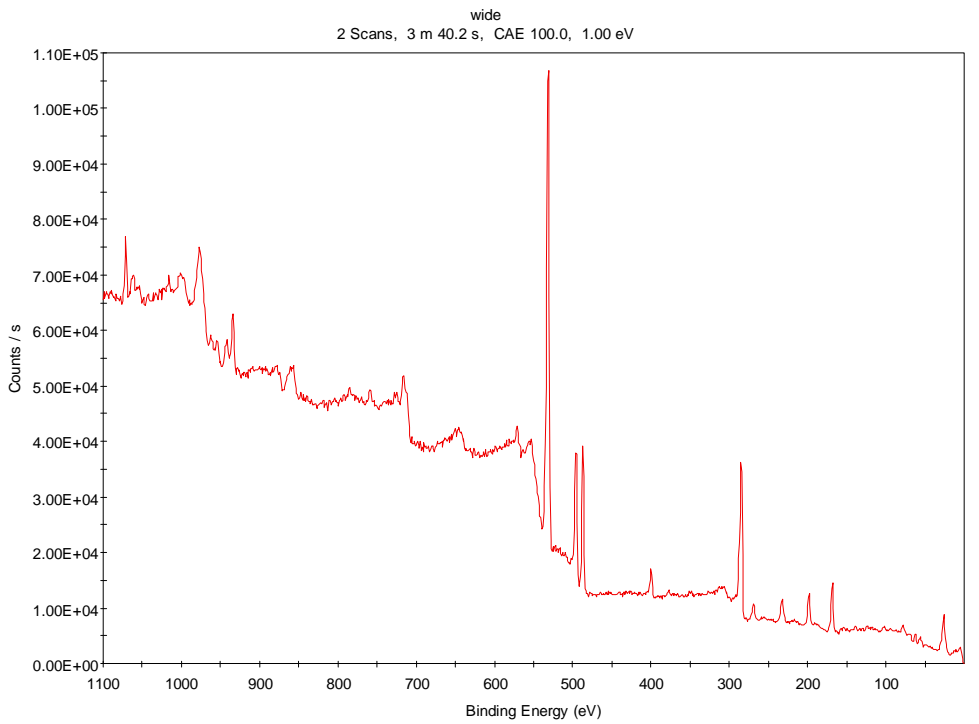

(b)

Fig. (13). Wide angle XPS spectrum for (a) activated carbon fibre electrode without any modification and (b) Ni modified carbon fibre electrode. 
concentration of exchanging solution whereas in case of nickel, the best performance was observed for $0.1 \mathrm{M}$ concentration compared to 0.2 and $0.5 \mathrm{M}$ concentration solutions. This can be explained by differences during the activation step. During the activation of carbon fibre electrode, the sulphate ion from $97 \% \quad \mathrm{H}_{2} \mathrm{SO}_{4}$ causes expansion of the carbon matrix and at the same time corrodes some of the carbon sites creating gaps in the matrix through which metal ions can intercalate to be exchanged with $\mathrm{H}^{+}$ions from the bulk. The ionic size of the sulphate ion dictates the amount of metal that can be exchanged during the ion exchange step. The $\mathrm{S}=\mathrm{O}$ bond length is $149 \mathrm{pm}$ while the diameter of sulphate ion is approx. $160 \mathrm{pm}$. The ionic diameters of $\mathrm{Cu}^{+2}$ and $\mathrm{Ni}^{+2}$ are $140 \mathrm{pm}$ and $160 \mathrm{pm}$ respectively. Copper ions due to their smaller ionic size can intercalate easily in and out of the matrix and hence show better electrocatalytic activity compared to metal ions with diameter greater than that of sulphate ion. Therefore nickel and palladium show very small amount of catalyst exchanged compared to smaller ions like copper on the surface.

\subsection{SEM Analysis}

Fig. (15) represents EDS results for nickel modified electrode which indicates the presence of nickel. SEM image for this electrode is represented in Fig. (16a) with the corresponding elemental mapping for nickel and sulphur shown in Fig. (16b).

\section{CONCLUSIONS}

Graphite fibre electrodes were fabricated by encasing a bundle of graphite fibres in resin and polishing the surface to expose their cross-section. These electrodes when modified by ion exchange with nickel behave similar to polycrystalline nickel electrodes and exhibit electrocatalytic activity towards the methanol oxidation reaction. The optimum working conditions for these electrodes were investigated and it was observed that the electrode modified

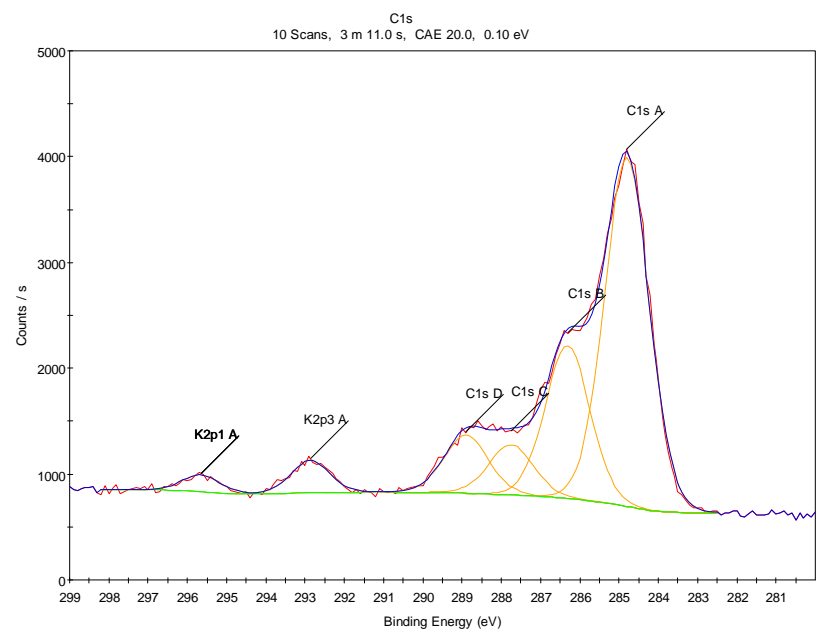

(a)

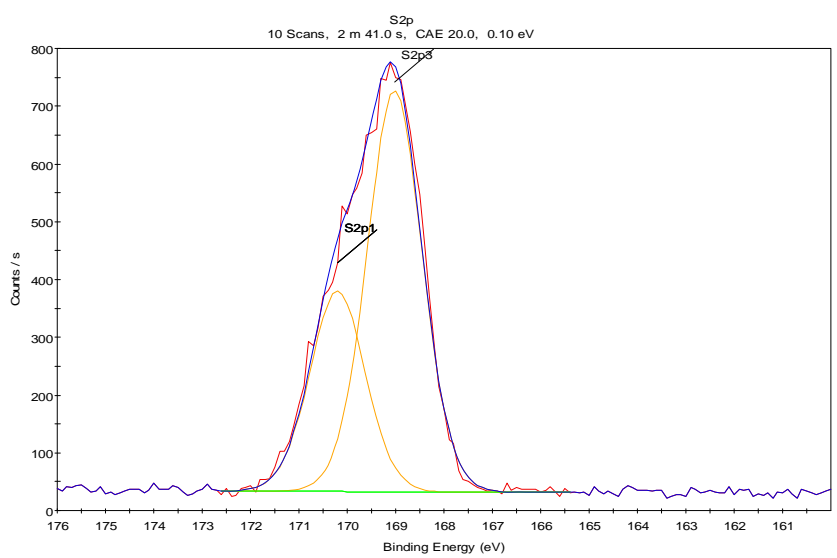

(c)

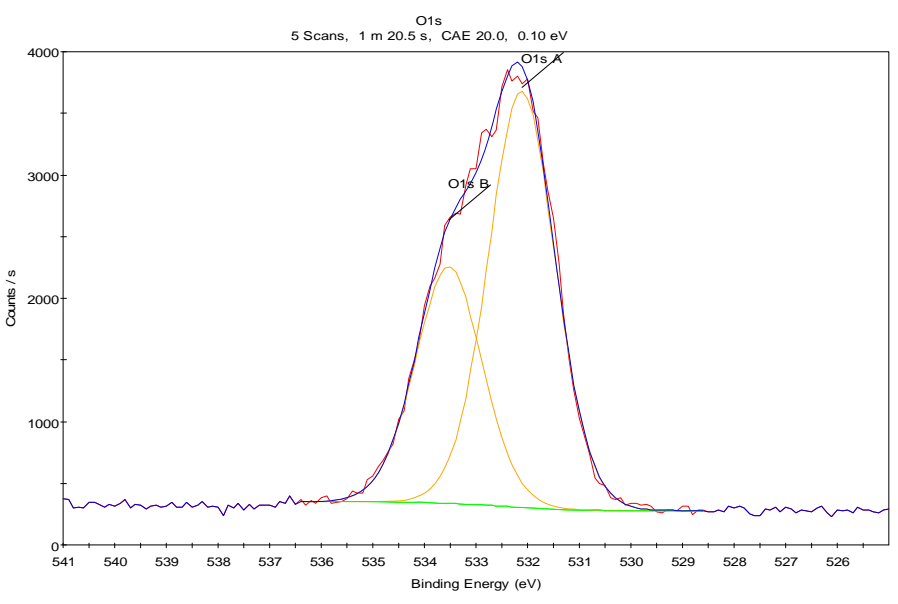

(b)

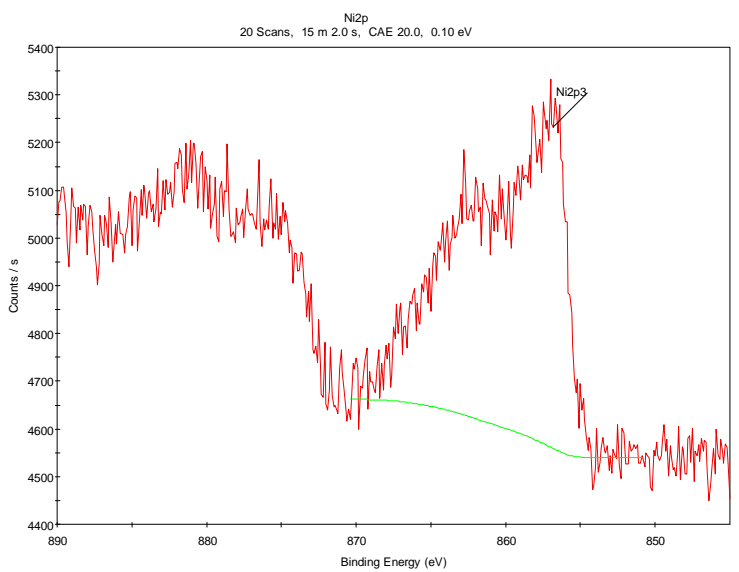

(d)

Fig. (14). XPS spectrum for carbon (a), oxygen (b), sulphur (c) and nickel (d) for Ni modified carbon fibre electrode. Only (a), (b) and (c) are present in case of activated carbon fibre electrode while (d) is absent. 


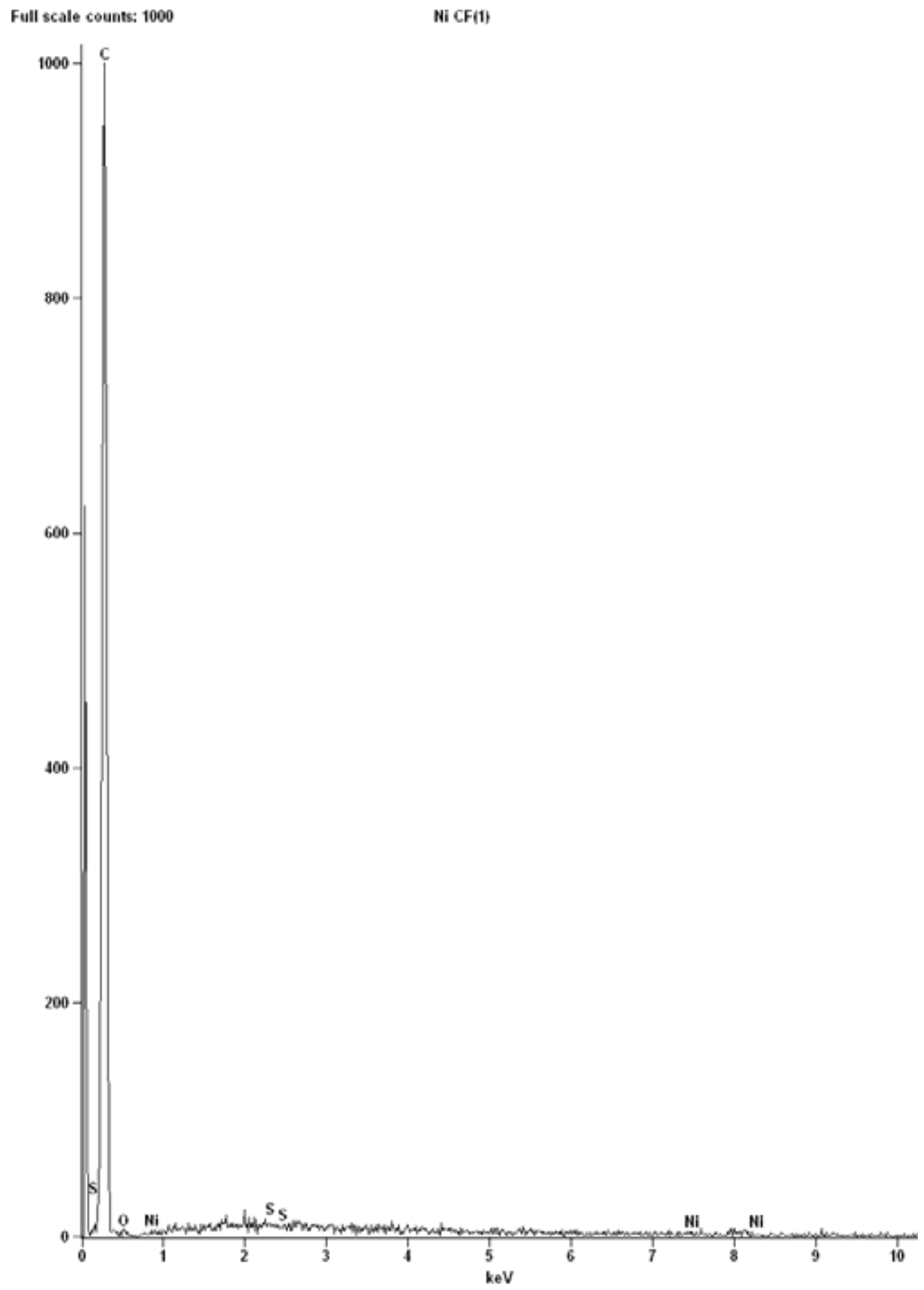

Fig. (15). EDS analysis for Ni modified electrode

by ion exchange in $0.1 \mathrm{M} \mathrm{Ni}$ solution provided the highest electrochemical activity with the highest methanol oxidation current observed at lower concentrations in the range of 0.1 $\mathrm{M}$ to $0.2 \mathrm{M}$ methanol in $0.5 \mathrm{M} \mathrm{NaOH}$ solution. At higher methanol concentrations the anodic peak current at the $0.1 \mathrm{M}$ $\mathrm{Ni}$ modified electrode decreased and this is believed to be due to poisoning of the $\mathrm{Ni}$ active sites by reaction products. Unlike electrodeposited nickel, the electrode prepared by this process, has nickel distributed in the carbon matrix instead of as continuous layer that may eventually passivate the surface during extended oxidation. By allowing electrical connectivity with the carbon matrix, the $\mathrm{Ni}$ modified graphite fibre electrode retains the electrocatalytic activity and hence shows better performance than nickel foil or electrodeposited $\mathrm{Ni}$.

\section{ACKNOWLEDGMENT}

None declared. 


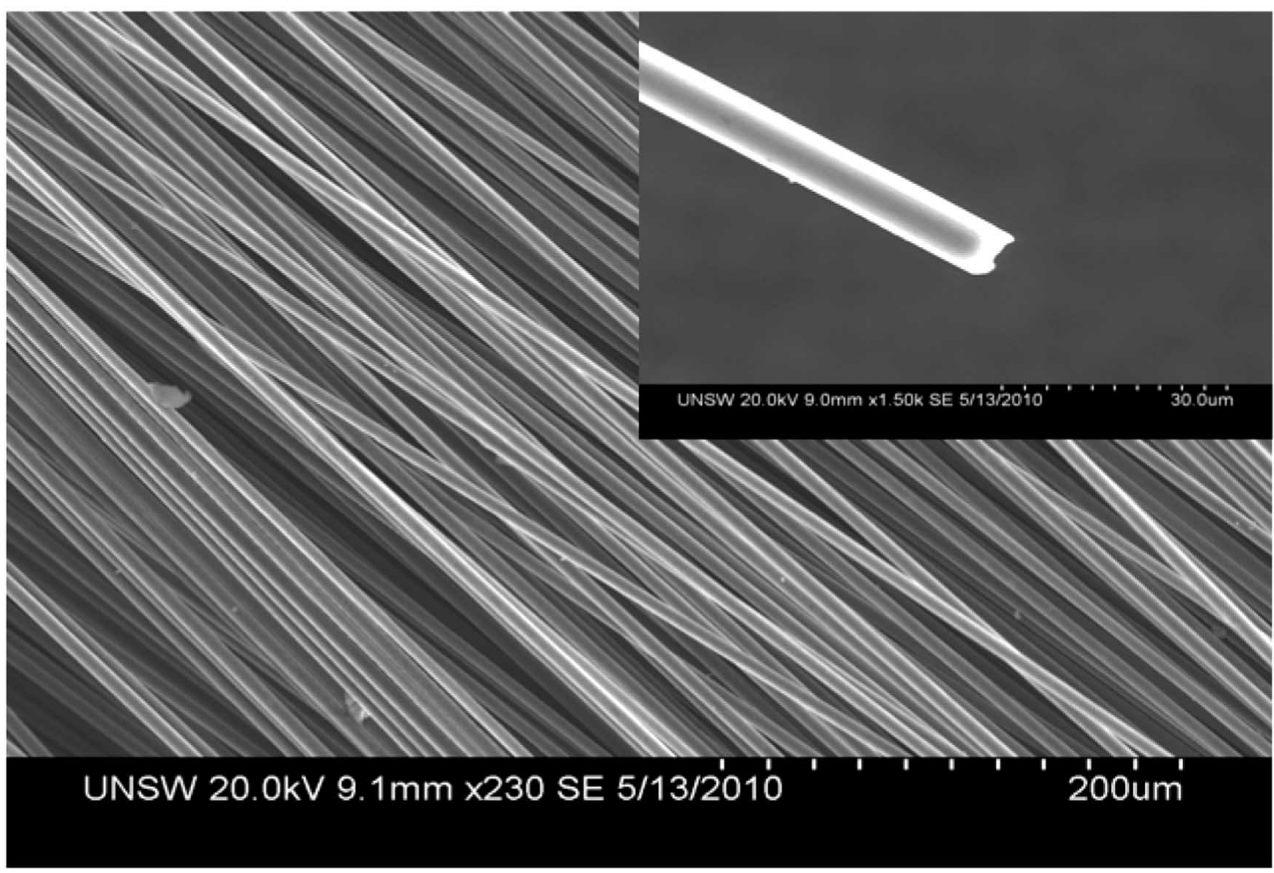

Ni CF(2)

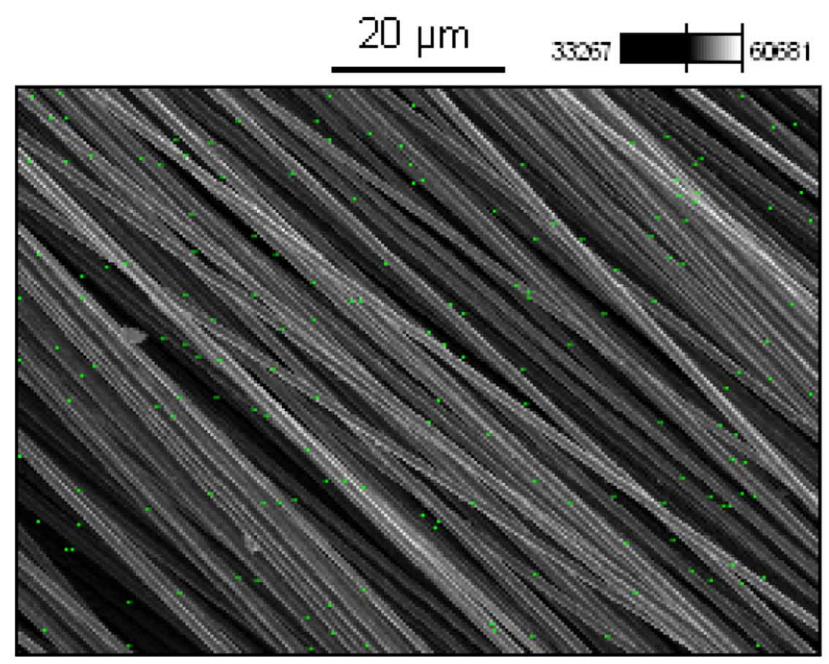

$\mathrm{Ni}$
Ni CF(2)

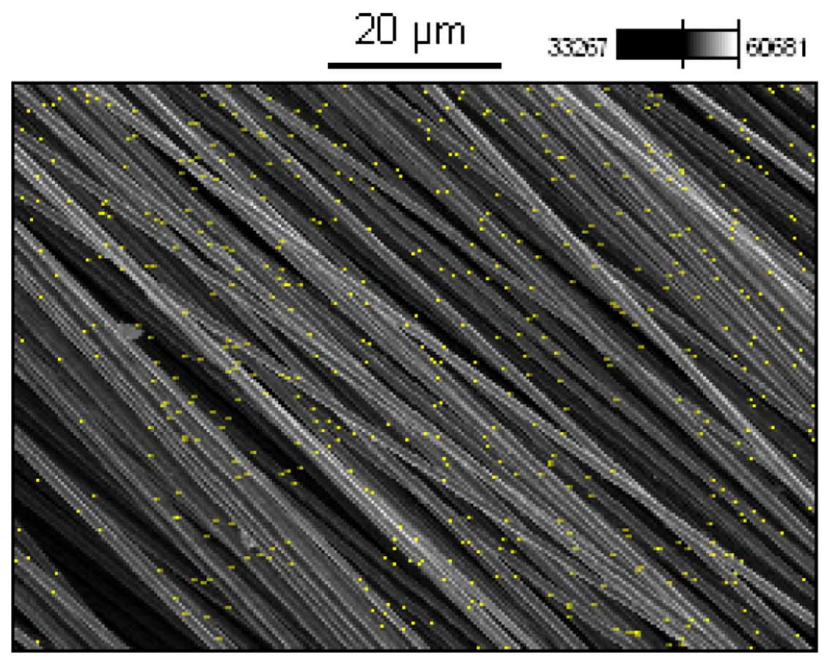

S

Fig. (16). SEM \& elemental mapping of $\mathrm{Ni}$ and $\mathrm{S}$ for nickel modified electrode with inset showing a single fibre.

\section{CONFLICT OF INTEREST}

None declared.

\section{REFERENCES}

[1] Mueller, J.T.; Urban, P.M. Characterization of direct methanol fuel cells by ac impedance spectroscopy. J. Power Sources, 1998, 75(1),139-143.

[2] Peled, E.; Duvdevani, T.; Aharon, A.; Melman, A. A direct methanol fuel cell based on a novel low-cost nanoporous proton conducting membrane. Electrochem. Solid-State Lett., 2000, 3(12), 525-528.

[3] Thomas, S.C.; Ren, X.; Gottesfeld, S. Influence of ionomer content in catalyst layers on direct methanol fuel cell performance. $J$. Electrochem. Soc., 1999, 146(12), 4354-4359.

[4] Iyuke, S.E.; Mohamad, A.B.; Kadhum, A.A.H.; Daud, W.R.W.; Rachid, C. Improved membrane and electrode assemblies for proton exchange membrane fuel cells. J. Power Sources, 2003, 114(2), 195-202.

[5] Sarma, L.S.; Lin, T.D.; Tsai, Y.-W.; Chen, J.M.; Hwang, B.J. Carbon supported Pt-Ru catalysts prepared by the Nafion stabilized alcohol-reduction method for application in direct methanol fuel cells. J. Power Sources, 2005, 139(1-2), 44-54.

[6] Arico, A.S.; Creti, P.; Kim, H.; Mantegna, R.; Giordano, N Antonucci V. Analysis of electrochemical characteristics of a direct methanol fuel cell based on a $\mathrm{Pt}-\mathrm{Ru} / \mathrm{C}$ anode catalyst. $J$. Electrochem. Soc., 1996, 143(12), 3950-3959.

[7] Iwasita, T. Electrocatalysis of methanol oxidation. Electrochim. Acta., 2002, 47(22-23), 3663-3674.

[8] Fujimoto, C.H.; Hickner, M.A.; Cornelius, C.J.; Loy, D.A. Ionomeric poly(phenylene) prepared by Diels-Alder polymerization: Synthesis and physical properties of a novel polyelectrolyte. Macromolecules, 2005, 38(12), 5010-5016. 
[9] Spendelow, J.S.; Wieckowski, A. Electrocatalysis of oxygen reduction and small alcohol oxidation in alkaline media. Phy. Chem. Chem. Phys., 2007, 9(21), 2654-2675.

[10] Tripkovic, A.V.; Popovic, K.D.; Grgur, B.N.; Blizanac, B.; Ross, P.N.; Markovic, N.M. Methanol electrooxidation on supported Pt and PtRu catalysts in acid and alkaline solutions. Electrochim. Acta., 2002, 47(22-23), 3707-3714.

[11] Spendelow, J.S.; Lu, G.Q.; Kenis, P.J.A.; Wieckowski, A. Electrooxidation of adsorbed $\mathrm{CO}$ on $\operatorname{Pt}\left(\begin{array}{lll}1 & 1 & 1\end{array}\right)$ and $\mathrm{Pt}\left(\begin{array}{lll}1 & 1 & 1\end{array}\right) / \mathrm{Ru}$ in alkaline media and comparison with results from acidic media. $J$. Electroanal. Chem., 2004, 568, 215-224.

[12] Cohen, J.L.; Volpe, D.J.; Abruna, H.D. Electrochemical determination of activation energies for methanol oxidation on polycrystalline platinum in acidic and alkaline electrolytes. Phy. Chem. Chem. Phy., 2007, 9(1), 49-77.

[13] Wang Z.B., Yin G.P., Zhang J., Sun Y.C., Shi P.F. Co-catalytic effect of $\mathrm{Ni}$ in the methanol electro-oxidation on $\mathrm{Pt}-\mathrm{Ru} / \mathrm{C}$ catalyst for direct methanol fuel cell. Electrochim. Acta., 2006, 51(26), 5691-5697.

[14] Hogarth, M.P.; Ralph, T.R. Catalysis for low temperature fuel cells Part III: Challenges for the direct methanol fuel cell. Platinum Metals Rev., 2002, 46(4), 146-164.

[15] Watanabe, M.; Genjima, Y.; Turumi, K. Direct methanol oxidation of Platinum electrodes with Ruthenium adatoms in hot phosphoric acid. J. Electrochem. Soc., 1997, 144(2), 423-428.

[16] Fleischmann, M.; Korinek, K.; Pletcher, D. The kinetics and mechanism of the oxidation of amines and alcohols at oxidecovered nickel, silver, copper and cobalt electrodes. J. Chem. Soc. Perkin Trans., 1972, 2(10), 1396-1403.

[17] Fleischmann, M.; Korinek, K.; Pletcher, D. The oxidation of organic compounds at a nickel anode in alkaline solution. $J$. Electroanal. Chem., 1971, 31(1), 39-49.

[18] Vertes, G.; Horanyi, G. Some problems of the kinetics of the oxidation of organic compounds at oxide-covered nickel electrodes. J. Electroanal. Chem., 1974, 52(1), 47-53.

[19] Robertson, P.M. On the oxidation of alcohols and amines at nickel oxide electrodes: mechanistic aspects. J. Electroanal. Chem., 1980, 111(1), 97-104.

[20] Roslonek, G.; Taraszewska, J. Electrocatalytic oxidation of alcohols on glassy carbon electrode electrochemically modified with nickel tetraazamacrocyclic complexes. J. Electroanal. Chem., 1992, 325(1-2), 285-300.

[21] Taraszewska, J.; Roslonek, G. Electrocatalytic oxidation of methanol on a glassy carbon electrode modified by nickel hydroxide formed by ex situ chemical precipitation. J. Electroanal. Chem., 1994, 364(1-2), 209-213.

[22] Losada, J.; del Peso, I.; Beyer, L. Redox and electrocatalytic properties of electrodes modified by films of polypyrrole nickel(II) Schiff-base complexes. J. Electroanal. Chem., 1998, 447(1-2), 147154.

[23] Ciszewski, A. Catalytic oxidation of methanol on a glassy carbon electrode electrochemically modified by a conductive Ni(II)curcumin film. Electroanalysis, 1995, 7(12), 1132-1135.
[24] Abdel Rahim, M.A.; Abdel Hameed, R.M.; Khalil, M.W. Nickel as a catalyst for the electro-oxidation of methanol in alkaline medium. J. Power Sources, 2004, 134(2),160-169.

[25] Watkins, B. F.; Behling, J. R.; Kariv, E.; Miller, L. L. Chiral electrode. J. Am. Chem. Soc., 1975, 97(12), 3549-3550.

[26] Firth, B. E.; Miller, L. L.; Mitani, M.; Rogers, T.; Lennox, J.; Murray, R. W.; Anodic and cathodic reactions on a chemically modified edge surface of graphite. J. Am. Chem. Soc., 1976, 98(25), 8271-8272.

[27] Lennox, J. C.; Murray, R. W. Chemically modified electrodes: VI. Binding and reversible electrochemistry of tetra-(aminophenyl) porphyrin on glassy carbon. J. Electroanal. Chem., 1977, 78(2), 395-401.

[28] Moses, P. R.; Wier, L.; Murray, R. W. Chemically modified tin oxide electrode. Anal. Chem., 1975, 47(12), 1882-1886.

[29] Armstrong, N. R.; Lin, A. W. C.; Fujihira, M.; Kuwana, T. Electrochemical and surface characteristics of tin oxide and indium oxide electrodes. Anal. Chem., 1976, 48(4), 741-750.

[30] Elliott C. M., Murray R. W. Chemically modified carbon electrodes. Anal. Chem., 1976, 48(8), 1247-1254.

[31] Puri B. R. Chemistry and Physics of Carbon; Marcel Dekker: New York, 1970, p. 191.

[32] Panzer, R. E.; Elving, P. J. Nature of the surface compounds and reactions observed on graphite electrodes. Electrochim. Acta., 1975, 20(9), 635-647.

[33] Randin J. P. In: Encyclopedia of Electrochemistry of the Elements; Bard, A. J., Ed.; Marcel Dekker: New York, 1976, p. 22.

[34] Boehm, H. P.; Diehl, E.; Heck, W.; Sappok, R. Surface oxides of carbon. Angew. Chem., 1964, 3(10), 669-677.

[35] Boehm, H. P. Chemical identification of surface groups. Adv. Cat., 1966, 16, 179-274.

[36] Barton, S. S.; Harrison, B. H. Acidic surface oxide structures on carbon and graphite. Carbon, 1975, 13(4), 283-288.

[37] Theodoridou, E.; Besenhard, J.O.; Fritz, H. P. Chemically modified carbon fibre electrodes: Part II. Characterization of trimethylsilanized carbon fibres by reduction of adsorbed onitrophenol. J. Electroanal. Chem., 1981, 124(1-2), 87-94.

[38] Theodoridou, E.; Jannakoudakis, A. D.; Jannakoudakis, D. Electrodeposition of metals after cation-exchange on modified carbon fibre electrodes. Synth. Met., 1984, 9(1), 19-30.

[39] Jannakoudakis, A. D.; Theodoridou, E.; Jannakoudakis, D. Electrochemical behaviour of platinized carbon fibre electrodes. Synth. Met., 1984, 10(2), 131-140.

[40] Sun, B.; Skyllas-Kazacos, M. Chemical modification and electrochemical behaviour of graphite fibre in acidic vanadium solution. Electrochim. Acta., 1991, 36(3-4), 513-517.

[41] Weinberg, N.L.; Reddy, T.B. Electrochemical oxidation of the surface of graphite fibres. J. Appl. Electrochem., 1973, 3(1), 73-75.

[42] Maximovitch, S.; Bronoel, G. Oxidation of methanol on nickel-zinc catalysts. Electrochim. Acta., 1981, 26(9), 1331-1338.

[43] NIST. X-ray Photoelectron Spectroscopy Database, Version 3.5; National Institute of Standards and Technology, Gaithersburg, 2003. Available at: http://srdata.nist.gov/xps/ 